\title{
Predicting supervisor capacities to foster higher forms of learning through undergraduate medical student research
}

\begin{abstract}
Margaret MacDougall ${ }^{1}$
Abstract: The credibility of short-term undergraduate research as a paradigm for effective learning within Medicine has been recognized. With a view to strengthening this paradigm and enhancing research-teaching linkages, this study explores whether particular types of research supervisor are pre-disposed to providing supportive learning environments. Correspondingly, a novel solution is offered to addressing clinical governance concerns about failings in preparing students for a supercomplex world. While recommendations for addressing these concerns have previously focused on curriculum delivery and assessment, this study affords a fresh perspective through consideration of research supervisor attributes, behaviours and experiences. Using statistical analyses of response data from a large cohort of experienced research supervisors who completed an online survey, evidence is found to suggest that staff involvement in personal research ought to enhance student learning through research. In turn, the supervisor factors which are most supportive of this effect may vary according to how we measure higher forms of learning. Supervisors are advised to design successive follow-on research projects to facilitate cross-disciplinary research. In preparing medical graduates for survival in a super-complex world, more needs to be done, however, to investigate why supervisors who see their students more regularly are more likely to provide cross-disciplinary research opportunities. By contrast, potential to engage in risk-taking behaviours and maintain or progress to an advanced stage of learning may originate more precisely with the student.
\end{abstract}

Keywords: cross-disciplinary research, research-teaching linkages, short-term research, supercomplexity, transitional learning, undergraduate medical students

If undergraduate medical student experiences of supervised short-term research are to reflect those of more senior researchers, it is inevitable that there will be considerable variation in the practices of their supervisors, both in terms of extent of involvement in the project and more specifically, with respect to how they design the research environment for the student. In the latter respect, the role of the supervisor "as an educator responsible for designing the research process to optimize student learning" (MacDougall \& Riley, 2010) is noteworthy insofar as this points to the potential for research supervisors to enhance research-teaching linkages.

The primary aim of the current study was to investigate, within the context of short-term research projects, the statistical evidence that specific supervisor factors have the potential to predict good supervisory practice, defined in terms of facilitating higher forms of student learning.

\footnotetext{
${ }^{1}$ Centre for Population Health Sciences, College of Medicine and Veterinary Medicine, University of Edinburgh. Margaret.MacDougall@ed.ac.uk
} 
Using survey data from supervisors of the above projects, this aim was addressed using the following approaches to hypothesis testing:

i) By means of a range of potential predictor variables, representing supervisor behaviours, characteristics or experiences, a number of study hypotheses were tested of the general form,

There is an association between the given potential predictor variable and given indicator of opportunity for higher form of student learning.

ii) Supervisor ratings of to what extent student research findings are revolutionary were compared according to a range of potential predictor variables representative of supervisor behaviours, characteristics and experiences. In this case, the study hypotheses were of the form,

a) there is a correlation between the given potential predictor variable and supervisor rating

or

b) there is a difference in supervisor rating across the categories of the given potential predictor variable.

The potential predictor variables to be considered were: number of students supervised to point of project completion (Q. 2), importance of research to supervisor's own PPD (Q. 23), how often supervisor meets with student (Q. 26), supervisor gender (Q. 29), supervisor age (Q. 30) and nature of supervisor's employment (Q. 35). In the case of ii), these were extended to include the outcome variables, considered under i). These outcomes variables comprised the following intended indicators of higher forms of learning, where 'PPD' denotes 'Personal Professional Development': whether supervisor has experience of supervising cross-disciplinary SSC4 projects (Q. 17), evidence of progression to or maintenance of advanced stage of learning as depicted by Baxter Magolda's Epistemological Reflection Model (Q. 19), extent of contribution of student to research life of department or team (Q. 22) and extent to which supervisor would encourage student to take risks (Q. 25). For the correlations investigated under a), the specific supervisor-focused potential predictor variables were number of students supervised to point of project completion, importance of research to own PPD and supervisor age.

A secondary aim of the current study was to test two particular cases of the study hypothesis time spent with student is associated with supervisor's degree of involvement in research. This involved the use of each of the importance of research to the supervisor's own PPD and the nature of the supervisor's employment as indicators of supervisor degree of involvement in academic research.

The incentive for the latter aim was that of addressing derogatory views expressed separately by Gibbs and Hughes with respect to the relationship between staff research activity and the quality of the student learning experience. Gibbs advocates the conventional view that staff being research active is a barrier to time spent with the student at an educational level. (Gibbs, 2002) This view is in turn reinforced by Hughes's cynical comments regarding the existence of a research-teaching nexus. Here, he portrays academics as defending the researchteaching nexus with a "vested interest" which can be traced to any one of the following explanations: "a Machiavellian desire to secure resources: a desire to protect an interesting piece of academic work; and self-interest of a small number of unrepresentative academics." (Hughes, 2005) Clearly, such cynicism invites a rejoinder. 
The above aims are grounded on the idea of recognizing the potential for the student research environment to be enhanced as a pedagogical tool in the hands of the research supervisor. The results of this investigation should therefore assist medical educators in evaluating their own pre-conceptions of which types of individual are best placed to optimize the quality of learning encountered through undergraduate medical student research. Such findings ought to be of interest to those involved in undergraduate research programmes more generally, particularly in the light of awareness that "research into undergraduate dissertation supervision is patchy" by comparison with that found in relation to postgraduate supervision. (Todd, Smith, \& Bannister, 2006) More specifically, however, these results should also inform programme organizers in recruiting suitable candidates for supervising future research projects.

This is a survey-based study and question numbers corresponding to the study questionnaire are referred to in brackets throughout this paper. The reader should also note that the questionnaire itself is included with this paper as an additional file under Appendix 1.

\section{Introduction}

\section{Context for student research}

Supervisor recommendations for initiating undergraduate medical students as fledgling researchers into the research culture of a team and as such, into what was perceived in this context as a research community of practice have already been explored. MacDougall \& Riley, 2010) As in the current study, the model of student research was that encountered by all survey respondents within the Year 4 Student Selected Component (SSC4) programme at the University of Edinburgh, Scotland. This mandatory programme involved clinically related projects, each of which typically ran over a 14-week period. Each project involved the submission of a project report of about 3,000 words. Two (possibly non-consecutive) weeks of the SSC4 period were allocated exclusively to SSC4 work. For the remainder of the time, students were expected to manage time spent on both SSC4 work and other curricular activities, including exam preparation. (MacDougall \& Riley, 2010) These projects were also recognized explicitly within the course materials as having the potential to increase student research skills and as counting toward summative assessment, with the project mark being assigned a weight of $14 \%$ in deciding end-of-year marks.

\section{Pedagogical Rationale for Choice of Indicators of Higher Forms of Learning}

Experience of Supervising Cross-Disciplinary Research and Extent to Which Supervisor Would Encourage Student to Take Risks. Within professional degree programmes, learning skills gained through enhanced learning experiences ought to be transferable to the workplace. This observation is consistent with Barnett's understanding of the University as carrying a responsibility to prepare its students for a phenomenon which he calls supercomplexity and represents in the following way:

...professional life is increasingly becoming a matter not just of handling overwhelming data and theories within a given frame of reference (a situation of complexity) but also a matter of handling multiple frames of understanding, of action and of self-identity. The fundamental frameworks by which we might understand the world are multiplying and are often in conflict. Of the 
multiplication of frameworks, there shall be no end. It is this multiplication of frameworks that I term supercomplexity. It increasingly characterizes the world in which we all live. (Barnett, 2000)

As such, supercomplexity is closely affiliated with Illeris's transformative learning concept of accommodation, according to which "one breaks down (parts of) an existing scheme or pattern and transforms it so that the new situation can be linked in." (Illeris, 2004) Here the need to "relinquish" and "reconstruct" is in keeping with the idea of forming alternative frames of reference, found within Barnett's notion of supercomplexity. Illeris also notes that for the learner, the above process can be both "demanding" and "painful" due to the initial experience of disorientation through loss of identity in what one knows, thus preparing educators for the pedagogical challenges that should arise in introducing students to situations of supercomplexity.

In the language of social identity theory, disorientation may also arise due to an ongoing need for the individual to redefine the categories which they have previously constructed to define their social identity as the member of a particular group. As Tajfel would have it, "we do not act as isolated individuals but as social beings who derive an important part of our identity from the human groups and social categories which we belong to, and we act in accordance with this awareness." (Tajfel, Jaspars, \& Fraser, 1984)

However, the development of supercomplexity gives rise to the need for such categories to be more pliable. Correspondingly, while from the perspective of social psychology, the natural tendency is for an individual's behaviour to be "ingroup stereotypical" (Hogg, 1996), this tendency needs to be conquered, as do the prejudices which reinforce intergroup boundaries. More specifically, as is particularly evident in Medicine, it is no longer possible to adopt the standpoint of social identity theory and self-categorization theory that "Correctness ... is a product of social agreement with others who are perceived as similar to self in the particular context." (Hogg, 1996) Likewise, while on the one hand, proponents of social identity theory argue that "people strive to positively differentiate their group from another as a means of further maintaining a positive self-esteem", (Fox, 1996) $21^{\text {st }}$ century medical graduates must be ready to define their personal professionalism in a less protectionist manner. The perception of physicians as "professionals of the establishment" inconvenienced by the objections of their "radical critics" (Schön, 1999) now belongs to a bygone age, which has been surpassed by that of public accountability. The physician must respect the patient voice. They must strive, therefore, to offer a credible evidence base for clinical decision-making which sheds new light on personal insights that patients bring to consultations.

The above challenges illustrate that supercomplexity is alien to the human psyche. As such, they lend weight to Barnett's conviction that within higher education, students need to be prepared for a supercomplex world. In particular, he identifies promotion of interdisciplinarity as one of two main conditions of the university in meeting its "responsibility to enable individuals to prosper amid supercomplexity through proliferating "frames of understanding." (Barnett, 2000, 2007)

To add to this, in the report of their most recent consultation of strategic options for undergraduate medical students the General Medical Council (GMC) express concerns about deficits in key features which can be seen as integral to preparedness for a supercomplex world. For example, they acknowledge the need "to make sense of the rapidly changing understanding of disease processes and treatment" together with the corresponding value of more training in basic science, as though the latter ought to serve the development of more robust frameworks of understanding for patient care. Likewise, they concede that in the UK, "We do not do enough to help students learn about dealing with uncertainty either for themselves or for their patients ... nor do we 
help them develop a repertoire of attributes to enable them to lead and contribute to change as well as to experience it." (GMC, 2006)

This evidence of medical governance support for preparing medical graduates for supercomplexity is reinforced by the intended outcomes for medical graduates recommended by the GMC and Royal College of Physicians and Surgeons of Canada (RCPSC). These include the capacity to consolidate multiple perspectives arising from patients, families and multidisciplinary healthcare teams (GMC, 2009) and to play a leading role in collaborative decision making in the face of uncertainty (RCPSC, 2005). Given that supercomplexity is an expanding international phenomenon, these concerns should not be limited to the UK. Also evident, however, is a lack of concrete recommendations as to how the above intended outcomes could be achieved. It is therefore intended that the current study should contribute to addressing this area of need, specifically within the context of supervision of undergraduate medical student research.

In establishing markers for higher forms of learning, Barnett's second condition for the university of fostering student capacity to live with uncertainty through risk-taking behavior is also of interest. This condition is closely tied with his concern that learners should be emancipated from the "conspiracy of safety" with its focus on "entrenching existing frames of understanding" (Barnett, 2000). Indeed, it is in response to this concern that exemplar supervisor practices to facilitate responsible risk-taking behaviour within undergraduate medical student research have recently been provided. (MacDougall, 2012)

In recognition of Barnett's above two conditions for supercomplexity, the queries raised through the study questionnaire were as follows:

Have you had the opportunity to supervise any cross-disciplinary SSC4 projects? (Q.17) and

During their SSC4 experience, to what extent would you encourage a given SSC4 student to take risks in exploring new areas of your subject and thus enter the unknown? (Q. 25)

Progression to or Maintenance of Advanced Stage of Learning. While supervisor responses to the above survey questions may serve as markers of enhanced student learning experiences, if they are to be authentic, such experiences also ought to involve transition to or maintenance of existing advanced approaches to learning. This indicator for higher forms of student learning can be assessed by Baxter Magolda's epistemological reflection model. (Baxter Magolda, 1992) Encouragingly so, the recent application of this model within the novel context of senior undergraduate medical student research has revealed that even short-term research, over 14-week periods, is associated with progression to higher forms of learning. (MacDougall, 2012) The supervisor responses that informed the above finding were collected according to a matrix of progression (Q. 19) comparing student learning stages immediately prior to and on completion of their SSC4 experiences. A natural next step was to consider which supervisor factors might contribute to the more positive of those responses.

Extent of Contribution of Student to Research Life of Department or Team. Communities of practice have gained popularity in teaching and learning theory under the recognition that they provide an environment for deep learning through the learner engaging in knowledge construction and negotiation. Correspondingly, evaluation of the quality of students' learning experiences in their roles as researchers ought to include assessment of evidence for their participation in research communities of practice. This need was recognized in the above questionnaire through including Output from SSC4 projects tends to make a constructive contribution to our knowledge of specific subject areas within one or more research programs among the available options for supervisors to choose from in expressing the contribution which their students tended to make to the research life of their department or team (Q. 22). 
Quality of Student Research Findings as Represented by Supervisor Ratings. Participation in communities of practice and preparedness for surviving in a supercomplex world should not, however, only be considered in isolation in assessing student learning experiences; rather, where research communities of practice are operational and the need for building student capacities to live with supercomplexity is recognized, there is also a call for an evaluation of the extent to which the learner is challenging existing frames of understanding within their community of research practice. A helpful model in this respect involves the representation of student research findings on a spectrum from norm endorsing to revolutionary, as in the follow question stem from the study questionnaire:

If the research findings of your SSC4 students were to be represented on a spectrum, from norm-endorsing (reinforcing what is already known) to revolutionary, how would you rate them overall? Use the drop-down menu below to record your answer, where a score of 1 represents 'norm-endorsing' and a score of 10 represents 'revolutionary'. (Q. 20)

This approach to recognizing enhanced learning is consistent with Barnett's observation that "[i]t is the revolutionary elements [of research] that are the motor of knowledge growth through the new frames of understanding that they bring." (Barnett, 2000)

\section{Research Supervision as Teaching}

In keeping with Connell's call for re-perception of research supervision as "a form of teaching" (Connell, 1985), the aims of this study are grounded on the idea of recognizing the student research environment as being enhanced as a pedagogical tool in the hands of the research supervisor. Connell's more recent retrospective account of how $\mathrm{PhD}$ supervision has traditionally been perceived is also pertinent, particularly her observation that "No one really thought this [PhD supervision] involved a form of education". (Connell \& Manathunga, 2012)

Nevertheless, Connell's emphasis on the one-to-one educational interchange between student and supervisor, particularly through the provision of feedback on student work, is quite distinct from the community of practice model which has served as a forerunner to the current study. Thus, for example, while Connell portrays her contribution to the pedagogy of (postgraduate) research as a "call to conversation" between the student and their supervisor (Connell \& Manathunga, 2012), the idea of the supervisor designing a research environment as a pedagogical tool for the fledgling researcher, as in this study, is more holistic.

This more holistic approach arises, not merely from a philosophical but also, from a practical perspective. It is likely that within an SSC4 research environment, where student performance affords a modest contribution to end-of-year marks, the stakes for the supervisor and student are considerably less. Correspondingly, students may typically have more freedom to roam and establish connections with other team members which are at least as significant for higher forms of learning as the supervisor-student relationship. Thus, Connell's observation that $\mathrm{PhD}$ supervision is "extremely difficult to do in a team" (Connell, 1985) is unlikely to be transferable in a general sense to the variety of student research experiences considered here. 


\section{Methods}

\section{Conduct of Survey and Data Preparation}

The current study is a follow-on study from two previous studies on research-teaching linkages. More comprehensive details of these particular studies, including full details of the conduct of the survey leading to the response data for the current study and of the relevant data preparation can be readily accessed through earlier papers. (MacDougall, 2012; MacDougall \& Riley, 2010)

\section{Statistical Analysis}

The data for this particular study were analyzed using IBM SPSS 19.0 (SPSS inc).

Associations between categorical variables were tested using the chi-square test of association, with Yates's continuity correction applied for two-by-two cases. The chi-square test of linear trend was also used to test for evidence for monotonic trends in:

i) proportion of supervisors with experience of supervising cross-disciplinary SSC4 projects according to number of students supervised to point of project completion;

and

ii) each of extent of contribution of student to research life of department or team and frequency of meetings according to importance of research to supervisor's $P P D$.

Where the proportion of expected counts of value less than 5 exceeded $20 \%$, Fisher's Exact test was used instead of the chi-square test of association. In such cases, the corresponding p-values are tagged with a '*' in the results section. Differences in supervisor ratings of student research across categories were examined using the Mann-Whitney U-test, while Spearman's rho ("rho") was used to assess the strength of correlation between supervisor rating of student research and each of number of students supervised to point of project completion and importance of research to own PPD. A statistical significance level of 0.05 was assumed throughout and a value for the square of rho of at least 0.3 was viewed as representative of a marked correlation.

\section{Results}

\section{Response Rates}

Out of a total of 324 , the number of respondents pertaining to the analyses for the current study ranged from 204 to 211 , thus representing 63.0 - $65.1 \%$ of the target population. Collectively, these respondents had SSC4 supervisory experience within the range of 125 - 129 clinical specialties.

\section{Experience of Supervising Cross-Disciplinary SSC4 Projects}

There was a lack of statistical evidence for a true association between experience of supervising cross-disciplinary SSC4 projects and any one of supervisor gender $\left(\chi^{2}=0.000\right.$, 
$\mathrm{p}=1.000, \mathrm{n}=205)$ and nature of supervisor's employment $\quad\left(\chi^{2}=0.041\right.$, $\mathrm{p}=0.839, \mathrm{n}=205)$, with $35 / 132(26.5 \%)$ males versus $20 / 73(27.4 \%)$ females responding positively and 36/130 (27.7\%) from (the category) non-academic or academic teaching versus $19 / 75$ (25.3\%) from (the category) academic research or academic research and teaching responding positively. By contrast, a statistically significant association was found between how often supervisor meets with student and experience of supervising cross-disciplinary SSC4 projects $\left(\chi^{2}=4.196, \mathrm{p}=0.041, \mathrm{n}=207\right)$, with $33 / 96(34.4 \%)$ of supervisors who met 4 or 5 times versus $23 / 111(20.7 \%)$ of supervisors who met 2 or 3 times responding positively.

The relationships between experience of supervising cross-disciplinary SSC4 projects and each of the remaining potential predictor variables are represented in Figures 1a) to c), below. In consistency with the relatively modest differences across categories evident from Figures 1b) and c), there was a lack of statistical evidence for a true association between the above outcome variable and any one of supervisor's age $\left(\chi^{2}=2.824, \mathrm{p}=0.588, \mathrm{n}=205\right)$ and importance of research to supervisor's $P P D\left(\chi^{2}=1.265, \mathrm{p}=0867, \mathrm{n}=207\right)$. By contrast, there was a highly significant association between this outcome variable and number of students supervised to point of project completion $(\mathrm{p}<0.0005, \mathrm{n}=211)$. The positive monotonic trend in experience of supervising cross-disciplinary SSC4 projects according to number of students supervised evident from Figure 1a) also proved to be highly significant $\left(\chi^{2}=27.719, p<0.0005\right.$, $\mathrm{n}=211)$.

\section{Progression to or Maintenance of Advanced Stage of Learning}

There was a lack of statistical evidence for a true association between evidence of progression to or maintenance of advanced stage of learning as depicted by Baxter Magolda's Epistemological Reflection Model and any one of supervisor gender $\left(\chi^{2}=0.018, \mathrm{p}=0.893, \mathrm{n}=\right.$ 204), nature of supervisor's employment $\left(\chi^{2}=0.000, \mathrm{p}=0.988, \mathrm{n}=204\right)$ and how often supervisor meets with student $\left(\chi^{2}=0.970, \mathrm{p}=0.325, \mathrm{n}=206\right)$, with $102 / 132(77.3 \%)$ males versus 57/72 (79.2\%) females responding positively, 100/129 (77.5\%) from non-academic or academic teaching versus 59/75 (78.7\%) from academic research or academic research and teaching responding positively and 78/96 (81.3\%) of supervisors who met 4 or 5 times versus $82 / 110(74.5 \%)$ of supervisors who met 2 or 3 times responding positively.

Likewise, there was a lack of statistical evidence for a true association between the above outcome variable and any one of number of students supervised to point of project completion $\left(\chi^{2}=10.131, \mathrm{p}=0.072, \mathrm{n}=210\right)$, importance of research to supervisor's PPD $\left(\chi^{2}=2.593\right.$, $\mathrm{p}=0.628, \mathrm{n}=206)$ and supervisor's age $\left(\mathrm{p}=0.748^{*}, \mathrm{n}=205\right)$.

\section{Extent of Contribution of Student to Research Life of Department or Team}

There was a lack of statistical evidence for a true association between extent of contribution of student to research life of department or team any one of supervisor gender $\left(\chi^{2}=\right.$ $1.055, \mathrm{p}=0.304, \mathrm{n}=205)$ and how often supervisor meets with student $\left(\chi^{2}=1.081, \mathrm{p}=0.298\right.$, $\mathrm{n}=207)$, with $35 / 132(26.5 \%)$ males versus $20 / 73(27.4 \%)$ females responding positively and $45 / 96(46.9 \%)$ of supervisors who met 4 or 5 times versus 43/111 (38.7\%) of supervisors who met 2 or 3 times responding positively. By contrast, a highly significant association was found between nature of supervisor's employment and extent of contribution of student to research life of department or team $\left(\chi^{2}=8.050, \mathrm{p}=0.005, \mathrm{n}=205\right)$, with $42 / 75(57.8 \%)$ from academic 
research or academic research and teaching versus 45/130 (34.6\%) from non-academic or academic teaching responding positively.

While there was a lack of statistical evidence for a true association between the outcome variable extent of contribution of student to research life of department or team and any one of supervisor age $\left(\chi^{2}=6.693, \mathrm{p}=0.153, \mathrm{n}=205\right)$ and number of students supervised to point of project completion $\left(\chi^{2}=7.370, \mathrm{p}=0.195, \mathrm{n}=207\right)$, this same outcome variable demonstrated a highly significant association with importance of research to supervisor's PPD $\left(\chi^{2}=31.265\right.$, $\mathrm{p}<0.005, \mathrm{n}=207)$.

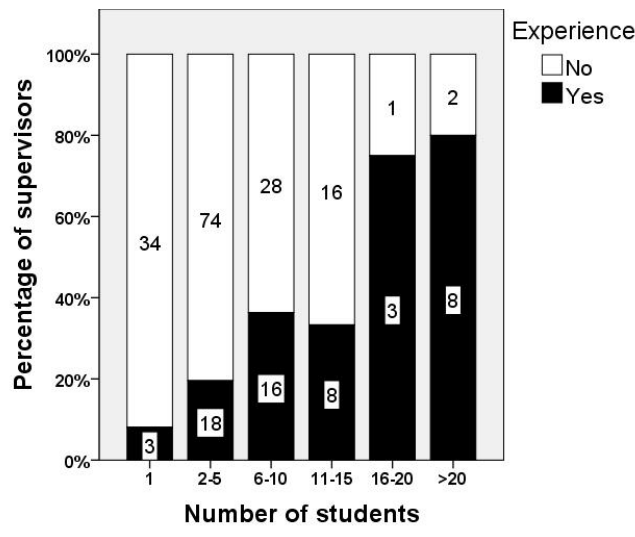

(a)

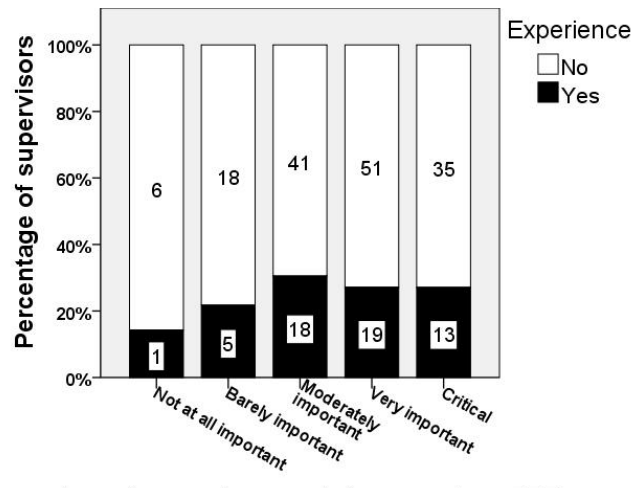

Importance of research to supervisor PPD

(c)

Figure 1. Supervisor experience in cross-disciplinary research according to (a) number of SSC4 students supervised to point of project completion, (b) supervisor's age and (c) importance of research to their personal professional development. Data are derived from responses to Q.'s 2, 17, 23 and 30. 'SSC4' denotes 'Year 4 Student-Selected Component'.

Indeed, in consistency with the distribution of the data in Figure 2, evidence was found for a positive monotonic trend in extent of contribution of student to research life of department or team according to level of importance of research to supervisor's PPD $\left(\chi^{2}=29.657\right.$, $\mathrm{p}<0.0005, \mathrm{n}=207)$. 


\section{Extent to Which Supervisor Would Encourage Student to Take Risks}

There was a lack of statistical evidence for a true association between the outcome variable extent to which supervisor would encourage student to take risks and any one of supervisor gender $\left(\chi^{2}=0.025, \mathrm{p}=0.875, \mathrm{n}=205\right)$, how often supervisor meets with student $\left(\chi^{2}=0.101, \mathrm{p}=0.751, \mathrm{n}=207\right)$ and nature of supervisor's employment $\left(\chi^{2}=0.066\right.$, $\mathrm{p}=0.797, \mathrm{n}=205)$, with $117 / 132(88.8 \%)$ of males versus $66 / 73(90.4 \%)$ females responding positively, 87/96 (90.6\%) of supervisors who met 4 or 5 times versus $96 / 111(88.3 \%)$ of supervisors who met 2 or 3 times responding positively and 115/130 (88.5\%) from nonacademic or academic teaching versus 68/75 (90.7\%) from academic research or academic research and teaching responding positively. There was also a lack of statistical evidence for a true association between the above outcome variable and any one of supervisor age $\left(\mathrm{p}=0.326^{*}, \mathrm{n}=205\right)$, number of students supervised to point of project completion, $\left(\mathrm{p}=0.293^{*}, \mathrm{n}=207\right)$ and importance of research to supervisor's $P P D\left(\chi^{2}=5.203, \mathrm{p}=0.267\right.$, $\mathrm{n}=207)$.

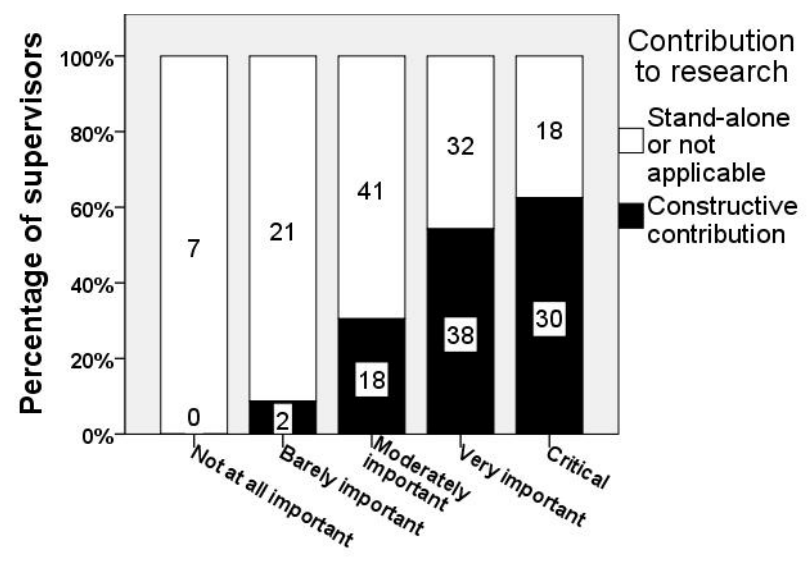

Importance of research to supervisor PPD

Figure 2. Contribution of student to research life of department or team according to importance of research to supervisor PPD. Data are derived from responses to Q.'s 22 and 23

\section{Quality of Student Research Findings as Represented by Supervisor Ratings}

There was a lack of statistical evidence for a marked correlation between supervisor rating of student research and any one of number of students supervised to point of project completion (rho $=0.092, \mathrm{p}=0.186, \mathrm{n}=209$ ), importance of research to own PPD $(\mathrm{rho}=0.048, \mathrm{p}=0.496, \mathrm{n}=207)$ and supervisor age $(\mathrm{rho}=0.243, \mathrm{p}<0.0005, \mathrm{n}=205)$.

The results of the group comparisons for quality of research findings based on the remainder of the extended list of potential predictor variables are provided in Tables 1 and 2.

\section{Challenging Critical Perspectives of Staff Involvement in Personal Research}

The data in Figure 3 represent the distribution of regularity of supervisor-student meetings according to importance of research to supervisor's PPD. 
With the exception of an initial dip, these data display a positive monotonic trend in frequency of meetings according to importance of research to supervisor's PPD, which was in turn found to be statistically significant $\left(\chi^{2}=4.500, \mathrm{p}=0.034, \mathrm{n}=210\right)$. However, there was a lack of statistical evidence for a true association between nature of supervisor's employment and how often supervisor meets with student $\left(\chi^{2}=0.000, \mathrm{p}=1.000, \mathrm{n}=205\right)$ with $60 / 130(46.2 \%)$ from non-academic or academic teaching versus 35/75 (46.7\%) from academic research or academic research and teaching reporting a tendency to meet with students 4 or 5 times.

Table 1

Group comparisons for supervisor ratings of research findings according to supervisor characteristics or behaviour. ${ }^{\text {a }}$

\begin{tabular}{|c|c|c|c|}
\hline & $\begin{array}{l}\text { mean } \\
\text { rank }\end{array}$ & range $^{b}$ & p-value \\
\hline \multicolumn{4}{|l|}{$\begin{array}{l}\text { How often supervisor meets } \\
\text { with student }\end{array}$} \\
\hline 4 or 5 times $(n=96)$ & 112.69 & $(1,10)$ & \\
\hline 2 or 3 times $(n=111)$ & 96.49 & $(1,9)$ & 0.049 \\
\hline $\begin{array}{l}\text { Supervisor gender } \\
\text { male }(n=132) \\
\text { female }(n=73)\end{array}$ & $\begin{array}{r}105.12 \\
99.16\end{array}$ & $\begin{array}{l}(1,10) \\
(1,9)\end{array}$ & 0.486 \\
\hline $\begin{array}{l}\text { Nature of supervisor's } \\
\text { employment } \\
\text { Non-academic or } \\
\text { academic teaching }(n=35)\end{array}$ & 99.18 & $(1,9)$ & \\
\hline $\begin{array}{l}\text { Academic research or } \\
\text { academic research and } \\
\text { teaching }(\mathrm{n}=75)\end{array}$ & 109.63 & $(1,10)$ & 0.219 \\
\hline
\end{tabular}

a. Data are derived from responses to Q.'s 20,26 and 29.

b. Range pertains to raw data 


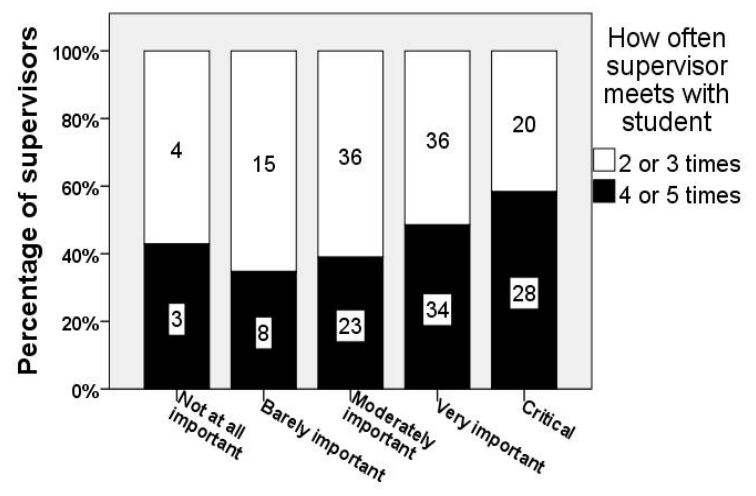

Importance of research to supervisor PPD

Figure 3. Number of times supervisor meets with student according to importance of research to supervisor's own PPD. Data are derived from responses to Q.'s 23 and 35.

Table 2

Group comparisons for supervisor ratings of research findings according to evidence for higher learning.

$\begin{aligned} & \text { mean } \\ & \text { rank }\end{aligned}$
Range p-value

Progression to or maintenance of advanced learning

\begin{tabular}{llll}
\hline Yes $(\mathrm{n}=162)$ & 111.65 & $(1,10)$ & \\
No $(\mathrm{n}=46)$ & 79.80 & $(1,7)$ & 0.001 \\
\hline $\begin{array}{l}\text { Supervisor has experience of } \\
\text { supervising cross-discipline research }\end{array}$ & & & \\
\hline Yes $(\mathrm{n}=56)$ & 108.99 & $(1,8)$ & \\
No $(\mathrm{n}=153)$ & 103.54 & $(1,10)$ & 0.560 \\
\hline $\begin{array}{l}\text { Extent to which risk-taking } \\
\text { encouraged }\end{array}$ & & & \\
\hline $\begin{array}{l}\text { At least somewhat or depends on the } \\
\text { student (n=185) }\end{array}$ & & & \\
Not al all or barely (n=22) & 67.27 & $(1,10)$ & 0.002 \\
\hline $\begin{array}{l}\text { Extent of student research } \\
\text { contribution }\end{array}$ & & & \\
\hline $\begin{array}{l}\text { Contructive contribution }(\mathrm{n}=88) \\
\text { Stand-alone or not applicable }(\mathrm{n}=119)\end{array}$ & 88.98 & $(1,8)$ & $\mathrm{P}<0.0005$ \\
\hline
\end{tabular}

a. data are derived from responses to Q.'s 23 and 35.

b. Range pertains to raw data 


\section{Discussion}

\section{General Observations}

Given the competing demands which are placed on clinicians, the relatively high proportion of respondent data available for the current study is encouraging, there being in excess of $60 \%$ for each statistical analysis. The lack of statistical evidence for supervisor gender contributing to opportunities for higher forms of learning is noteworthy. While male and female supervisors may differ in their tendencies toward particular styles of supervision, (Hammick \& Acker, 1988), there is no reason to assume from this study that such differences reflect a supervisor gender bias in rating of the revolutionary dimension of student research or indeed, of capacity to assume the role of the effective educator.

\section{Experience of Supervising Cross-Disciplinary SSC4 Projects}

The finding of this study that there was a significantly greater tendency for supervisors who met more often with their students to have supervised cross-disciplinary research provides a useful basis for qualitative research. In particular, longitudinal data might strengthen and explain the possibility that choosing to supervise cross-disciplinary research places an extra burden on supervisors. The increasing monotonic trend in experience of this type of supervision according to number of students supervised to point of completion (Figure 1a) may provide further groundwork in this respect. In particular, there is a need to explore whether cross-disciplinary projects attract more students or whether a greater level of supervisory experience, both in terms of number of students and time spent with individuals, empowers the research supervisor to design cross-disciplinary research. The relatively modest proportion of approximately $27 \%$ of supervisors having supervised cross-disciplinary research (Figure 1) together with the relative consistency of this statistic across levels of importance of research to supervisor PPD (Figure 1c)) would appear to suggest that supervisor perceptions of their own PPD as researchers do not involve giving precedence to cross-disciplinary work. This finding may be a reflection of the tension between balancing the demands of clinical practice with the additional time involved in developing interdisciplinary research partnerships and grant applications. However, from a pedagogical perspective, supervisors need to be better placed to provide opportunities for students to develop skills for managing supercomplexity in the workplace.

There is a particular call for tailoring student research opportunities to involve competing frameworks so as to ensure that undergraduate medical students are exposed to further opportunities to engage in cross-disciplinary research. This invites a closer examination of how clinical research profiles are defined at the recruitment stage and what incentives and innovations may need to be introduced to promote cross-disciplinary research within Medicine. Future work addressing this need should also involve clinicians who do not supervise student research. This would help in verifying whether it is more precisely the case that clinicians who are most engaged in cross-disciplinary research tend to be too busy to take on the role of supervising undergraduate research. Such questions demand an answer if we are to identify successful strategies for creating cross-disciplinary research opportunities for tomorrow's doctors.

There is a lack of adequate statistical evidence from this study that supervisor age is likely to influence their involvement in supervision of cross-disciplinary research. Nevertheless, given that the corresponding group sizes according to age are relatively unbalanced (Figure 1b),

Journal of the Scholarship of Teaching and Learning, Vol. 14, No. 1, February 2014. 
statistical power is likely to have been attenuated considerably in assessing this particular association. This being the case, the differences in the proportions evident from this figure should not be discounted; rather, they promote further investigation in a larger study which can accommodate more data to represent the extreme age-groups.

\section{Progression to or Maintenance of Advanced Stage of Learning}

Interestingly, while none of the potential predictor variables considered in this study were able to differentiate between research supervisors according to student progression to or maintenance of an advanced stage of learning as depicted by Baxter Magolda's Epistemological Reflection Model, there was a highly significant difference in supervisor ratings of research findings according to this outcome variable (Table 2). In particular, there was a tendency for supervisors who responded positively in terms of Baxter Magolda's model to rate research findings more closely to revolutionary (Table 2). This suggests that while supervisor characteristics, behaviours and experiences may not feature highly in facilitating maintenance of or progression to advanced learning in Baxter Magolda's sense, the latter indicator of highquality learning is closely connected with a movement away from norm-endorsing approaches to research. As such, it is affiliated with Barnett's ideals of "knowledge growth" and "building of new frames of understanding", thus equipping the medical graduate to thrive in a world of supercomplexity. (Barnett, 2000)

To further support research in learning development, a longitudinal study in which student and supervisor response data are linked could explore the student factors associated with students being perceived by their supervisors as having progressed to or maintained advanced stages of learning.

\section{Extent of Contribution of Student to Research Life of Department or Team}

The results of this study reveal that the nature of supervisors' employment may have an important role to play in capacity to facilitate student participation in research communities of practice. In particular, supervisors who view themselves as academic researchers may be more likely to be prolific in opening opportunities for student contributions to knowledge construction. In terms of promoting deeper learning experiences for students, clinicians who recognize their employment roles as non-academic may therefore need to negotiate with their management teams in allowing protected time for personal research. Progress in this area ought to enable 'non-academic' supervisors to gain sufficient insight into the constituents of a given research field to provide constructive learning opportunities for their students.

The potential for adaptation of 'non-academic' career roles to reap benefits for student learning in the above sense is reinforced by additional findings from this study. In particular, once research involvement becomes an integral component of what supervisor's perceive as legitimate PPD, students may be better placed to join communities of research practice. This is evident from the high level of statistical evidence for:

a) an association between extent of contribution of student to research life of department or team and importance of research to supervisor's PPD

and

b) a positive monotonic trend in likelihood of student making a constructive contribution to research life of department or team according to importance of research to 
supervisor's PPD.

In terms of improving research supervision skills to enhance student learning, there is a clear challenge in persuading medical graduates with a heavy clinical workload to take time out for training in pedagogical theory designed to make them more effective educators. However, while clinicians continue to take on opportunities to supervise undergraduate research opportunities the pedagogical role of these responsibilities needs to be driven home. Of interest here, are the relevant staff development workshops or distance learning materials available within the UK. Depending on the needs expressed by the particular university, these are provided for supervisors of science or medical students at the undergraduate or postgraduate level at Universities of Birmingham; Cranfield; Leeds; Newcastle; Nottingham and Southampton and St George's, University of London. These pathways for mapping research supervision to pedagogy expose staff to a range of supervisory scenarios, while preparing them for defining staff-student boundaries and avoiding students having false starts due to poor research design. (Kate Exley, personal correspondence) Furthermore, Epigeum (http://www.epigeum.com/) is a recognized leading publisher of online courses for enhancing the quality of research with a mission to "transform the way in which universities and colleges support their core activities of research, teaching and learning." Given adequate funding, much could be learnt from merging ongoing activities associated with the above initiatives with the practical ideas forthcoming from the current study.

\section{Extent to which Supervisor Would Encourage Student to Take Risks and Quality of Student Research Findings as Represented by Supervisor Ratings}

As an indicator of higher forms of learning, extent to which supervisor would encourage student to take risks shares some common ground with progression to or maintenance of an advanced stage of learning as depicted by Baxter Magolda's Epistemological Reflection Model, there being a lack of statistical evidence for an association between this variable and any of the corresponding potential predictor variables. This is partly a reflection of the result that most supervisors reported that they would encourage a given student at least somewhat to take risks, irrespective of the category to which the supervisor belonged. The above two indicators of higher forms of learning were also compatible in relation to their role as potential predictors of quality of student research findings as perceived by supervisor. Here, higher mean ranks and maximum raw scores occurred for supervisors who responded positively and statistically, these results were found to be highly significant.

These findings are consistent with the idea that there may be inherent attributes of the student researcher which make them more predisposed to being recognized by their supervisors as potential risk takers or transitional learners over and above the behaviours, characteristics and experiences of their supervisors. A clearer understanding of what student factors could lead supervisors to encourage student to take risks and promote maintenance or progression to an advanced stage of student learning may help in identifying those students who are likely to be rated most highly within a given research setting. Through analysis of pre-existing student survey response data, this work is to be pursued in relation to risk-taking opportunities in particular. The outcome of interest in terms of opportunity for higher form of learning will be the student's own response to a comprehensive question pertaining to the extent to which their supervisor(s) encouraged risk-taking. Potential predictive factors for which data have already been collected include, among others, prior research experience of student, specialisms covered 
by student in SSC4 research project and extent of mutual trust between student and at least one more experienced colleague that the student would make a valuable contribution to the project. For the purpose of future research, it is also of interest to note that the capacity of a particular student to engage with risk-taking opportunities may be dependent on their inherent readiness to trust the orchestrator - in this case, the supervisor - and their perception of self-efficacy.

The findings in Table 1 suggest that supervisor rating of student research is dependent on regularity of student-supervisor meetings, with supervisors who tended to meet more regularly with their students being significantly more likely to rate their students higher. This certainly makes sense in terms of less contact hours being a potential barrier for students aspiring to more revolutionary forms of research. The highly significant finding in terms of supervisors being more likely to score students highly if they were perceived as making a constructive contribution to their community of research practice (Table 2) is consistent with the idea that supervisors perceive knowledge construction on the part of the student as challenging existing norms. This would suggest that either the supervisors involved in this study have high expectations of what is entailed by knowledge construction or students who engage in knowledge construction tend do so in a revolutionary manner. These alternatives may need to be teased apart through qualitative research examining the nature of individual student research projects in conjunction with supervisor ratings.

Supervisory experience of cross-disciplinary research did not feature as an important factor in predicting supervisor research ratings of their students. Possibly, the extra time involved in the collaborative element of interdisciplinary projects, including establishing connections between the student researchers and significant others, (MacDougall \& Riley, 2010) restricts the scope for progressing to a revolutionary endpoint within the time-frame of a short research project. Correspondingly, perhaps such projects could be more optimally designed with considerable foresight and planning as follow-on projects for students in succession. Thereby, endpoints of a more revolutionary nature ought to be attainable and students involved in the early stages of the research advised of the potential importance of their input to cutting-edge research, albeit much further down the line.

\section{Challenging Critical Perspectives of Staff Involvement in Personal Research}

The results arising from an investigation of the relationships between supervisor involvement in personal research and time spent with the student are instructive and encouraging. In particular, they reveal evidence that time spent with the student increases with importance of research to supervisor's PPD. Taking undergraduate research to constitute an effective medium for deep learning, this finding provides evidence for the existence of a learning context where there is a positive synergy between supervisor research productivity and availability to meet student learning needs. Also noteworthy is the very pronounced lack of statistical evidence for a true difference in time spent with the student according to nature of supervisor's employment. Such findings suggest that Gibbs's and Hughes's perspectives on the research-teaching nexus may be biased. Nevertheless, there is also a need for further qualitative research exploring the nature of student learning during supervisor-student contact hours so as to verify that student learning needs are being prioritized above those of the supervisor's personal research agenda. 


\section{Limitations}

Since 165/206 (80.09\%) of respondents specified their ethnicity as White British and remaining respondents were thinly divided across other ethnicity categories, the response data did not support the investigation of supervisor ethnicity as a potential predictive factor in relation to extent to which supervisor would encourage student to take risks; otherwise, this would have been an interesting relationship to explore, recognizing that culture may be associated with openness to risk-taking.

\section{Conclusions}

The maintenance of enhanced student learning experiences in undergraduate medical student research cannot simply be taken for granted but must be continually worked on. A key element of this responsibility as it presents itself to course organizers is that of recognizing, highlighting and promoting supervisor attributes, behaviours and experiences which are supportive of these experiences. While this study reveals that these factors may vary considerably according to how we choose to define higher forms of learning, there is also a call to explore the relevance of student attributes in determining whether such learning is possible for any given student.

The findings of this particular study also contribute a pragmatic element to addressing clinical governance concerns about failings in preparing students for a supercomplex world. In particular, investigation of the types of supervisor best suited for preparing students for a supercomplex world has led to the identification of possible links between amount of supervisory experience and student openings for cross-disciplinary research and a call for a closer examination of how these links are established.

Inclusion of risk-taking opportunities for students in the above investigation has revealed a lack of evidence that particular categories of supervisor are more predisposed to designing the research environment to enable students to encounter risk. The replication of this finding on considering student capacity to maintain or progress to an advanced stage of learning, as defined by Baxter Magolda's epistemological reflection model ought to be viewed positively in terms of equality of opportunity for students to engage in higher forms of learning. On the other hand, there appears to be substantive evidence from this study to suggest that the determinants of higher forms of learning as defined by the above two outcome variables may originate more precisely with the student.

The scope for students to make constructive contributions to their research communities of practice appears to be positively linked with level of involvement of supervisor in research both as defined by their job role and by the extent to which they recognize research as important to their PPD. In terms of the capacity for deep learning, this result highlights the importance of supervisor participation in personal research for ensuring that undergraduate medical student research can serve as a successful paradigm for effective learning.

In promoting this finding as a basis for reform in supervisor training, it is encouraging to note that the results of this particular study are unsupportive of the view that student learning experiences are likely to be compromised on account of the research activities of their educators. This does not rule out the possibility, however, that staff who opt out of supervising undergraduate research on grounds of personal research commitments spend less time with their students in mandatory teaching roles, nor can we be sure that increased supervisor-student

Journal of the Scholarship of Teaching and Learning, Vol. 14, No. 1, February 2014. 
contact hours in the case of research-orientated supervisors is symptomatic of greater attentiveness to student learning needs. Such observations have paved the way for future research in enhancing the quality of student learning.

\section{Acknowledgements}

Appreciation is extended to the Medev subject centre of the Higher Education Academy (HEA) for funding the research for this study under the project 'Research-based SSCs: a pragmatic approach to advancing the research-teaching nexus in UK medical schools' (ref: 549). Thanks are also due to Mr Nigel Purcell (HEA Senior Education Adviser) for approving this research in his capacity as HEA contact for the project, all research supervisors who very generously gave of their time to respond constructively to the survey, Mr Nicholas Bowskill (Kelvin-Smith Scholar, University of Glasgow) for useful pointers to social identity theory and the work of Tajfel, Dr Kate Exley (Senior Staff Development Officer, University of Leeds and Director, HE Assessment and Development Ltd) for an illuminating discussion on existing professional pathways for enhancing pedagogical skills of research supervisors, Ms Lisa Ketchion (previously Secretary for Student Selected Components (SSCs)), University of Edinburgh for her assistance in obtaining supervisor contact details, Dr Simon C Riley, Director of SSCs at the University of Edinburgh for carrying out a confirmatory check of the survey questionnaire prior to distribution and to the anonymous reviewers for their constructive role in enhancing the quality of this paper.

\section{Appendix}

Appendix 1. Research Supervisor Questionnaire.

The full survey can be found at http://josotl.indiana.edu/article/view/3245/4661.

\section{References}

Barnett, R. (2000). Realizing the University in an Age of Supercomplexity. Philadelphia, PA: The Society for Research into Higher Education and Open University Press.

Barnett, R. (2007). A Will to Learn: Being a Student in an Age of Uncertainty. New York, NY: The Society for Research into Higher Education.

Baxter Magolda, M. B. (1992). Knowing and Reasoning in College: Gender-Related Patterns in Students' Intellectual Development. San Francisco, CA: Jossey-Bass.

Connell, R. (1985). How to supervise a PhD. Vestes: Australian Universities Review, 28(2), 38 41.

Connell, R., \& Manathunga, C. (2012). On doctoral education: how to supervise a PhD, 1985 2011. Australian Universities Review, 54(1), 5 - 9. 
Fox, S. A. (1996). "Let the Wheelchair Through!": An Intergroup Approach to Interability Communication. In W. P. Robinson (Ed.), Social Groups and Identities: Developing the Legacy of Tajfel (pp. 215 - 248). Oxford, UK: Butterworth-Heinemann.

Gibbs, G. (2002). Institutional strategies for linking research and teaching. Focus, 3, 8 -11.

GMC. (2006). Strategic Options for Undergraduate Medical Education - Final Report Source: http://www.gmc-uk.org/strategic_outcomes_final_report_jun_2006.pdf_25397182.pdf.

GMC. (2009). Tomorrow's doctors: Outcomes and standards for undergraduate medical education. Retrieved from http://www.gmcuk.org/static/documents/content/GMC_TD_09_1.11.11.pdf

Hammick, M., \& Acker, S. (1988). Undergraduate research supervision: a gender analysis. Studies in Higher Educaton, 23(3), 335 - 347. doi: 10.1080/03075079812331380296

Hogg, M. A. (1996). Intragroup Processes, Group Structure and Social Identity. In W. P. Robinson (Ed.), Social Groups and Identities: Developing the Legacy of Tajfel (pp. 65 -93). Oxford, UK: Butterworth-Heinemann.

Hughes, M. (2005). The Mythology of Research and Teaching Relationships in Universities. In R. Barnett (Ed.), Reshaping the University: New Relationships Between Research, Scholarship and Teaching. Berskshire, UK: Society for Research into Higher Education and Open University Press.

Illeris, K. (2004). Transformative learning in the perspective of a comprehensive learning theory. Journal of Transformative Education, 2(2), 79 - 89. doi: 10.1177/1541344603262315

MacDougall, M., \& Riley, S. C. (2010). Initiating undergraduate medical students into communities of research practise: What do supervisors recommend? BMC Medical Education, $10(83)$.

MacDougall, M. (2012). Research-teaching linkages: Beyond the divide in undergraduate Medicine. International Journal for the Scholarship of Teaching and Learning, 6(2).

RCPSC. (2005). CanMEDS 2005 Framework. Retrieved from http://www.royalcollege.ca/portal/page/portal/rc/common/documents/canmeds/framework/the_7 _canmeds_roles_e.pdf

Schön, D. A. (1999). The Reflective Practitioner: How Professionals Think in Action. Aldershot, Hampshire, UK: Ashgate (First published 1983).

Tajfel, H., Jaspars, J. M. F., \& Fraser, C. (1984). The social dimension in European social psychology. In H. Tajfel (Ed.), The social dimension: European developments in social psychology. Cambridge, UK: Cambridge University Press. 
MacDougall, M.

Todd, M. J., Smith, K., \& Bannister, P. (2006). Supervising a social science undergraduate dissertation: staff experiences and perceptions. Teaching in Higher Education, 11(2), 161 - 173. 